\title{
ISOLASI DAN SKRINING MIKROALGA AIR TAWAR SEBAGAI SUMBER PIGMEN KAROTENOID
}

\author{
Arif Juliari Kusnanda ${ }^{1}$, Bayu Afnovandra Perdana1 , Abdi Dharma¹, \\ dan Zulkarnain Chaidir ${ }^{1}$ \\ 1)Jurusan Kimia, Fakultas Matematika dan IImu Pengetahuan Alam, Universitas Andalas \\ Kampus Limau Manis, Padang, West Sumatera, 25163, Indonesia \\ Tel./fax. (+62) 751 - 71671 \\ E-mail: zulkarnaian_ch@yahoo.co.id
}

Received : 15 Februari 2021; revised : 15 Maret 2021 ; accepted : 9 April 2021

\begin{abstract}
ABSTRAK
ISOLASI DAN SKRINING MIKROALGA AIR TAWAR SEBAGAI SUMBER PIGMEN KAROTENOID Mikroalga menjadi salah satu sumber senyawa aktif yang memiliki potensi sebagai sumber pangan fungsional sebagai antioksidan seperti karotenoid. Penelitian ini bertujuan untuk mengisolasi mikroalga dari sumber perairan air tawar dan melakukan penapisan terhadap mikroalga sebagi sumber karotenoid. Mikroalga diisolasi dengan menggunakan mikropipet dan dikultivasi dalam media Bold's Basald Medium (BBM). Penentuan tingkat pertumbuhan dengan spektrofotometer UV-Vis, penentuan berat biomassa kering secara gravimetri, skrining total karotenoid dilakukan menggunakan metode Lichtenthaller dengan spektrofotometer UV-Vis. Berdasarkan hasil penelitian diperoleh empat spesies mikroalga dengan warna hijau yang menandakan semuanya merupakan golongan mikroalga chlorophyta (alga hijau). Skirining total karotenoid dilakukan terhadap empat spesies hasil isolasi dan dua spesies mikroalga dari Laboratorium Biokimia yaitu Scenedesmus rubescens dan Galdiera sulphuraria. Hasil skrining kandungan total karotenoid tertinggi adalah mikroalga hasil isolasi dari air kolam dengan yang merupakan genus chlorophyta sebesar $36 \pm 0,25 \mu \mathrm{g} / \mathrm{g}$. Hasil ini memberikan informasi isolat mikroalga hasil isolasi dapat dijadikan sebagai mikroalga potensial sebagai sumber dan produksi karotenoid.
\end{abstract}

Kata kunci : isolasi, mikroalga, karotenoid,

\begin{abstract}
ISOLATION AND SCREENING OF FRESH WATER MICROALGES AS A SOURCE OF CAROTENOID PIGMENT Microalgae are source of bioactive compounds that have potential as a source of functional food for antioxidants such as carotenoids. The aims of this study were to isolated microalgae from freshwater sources and to screening carotenoids from biomass microalgae. Microalgae were isolated using micropipettes and were cultivated in bold's basald medium (BBM). Determination of growth rates was performed using a UV-Vis spectrophotometer,dry biomass was determined using gravimetric and total carotenoid screening was carried out using the Lichtenthaller method employing a UV-Vis spectrophotometer. Four species of microalgae were obtained with a green color indicating that all of them are chlorophyta (green algae) microalgae. Screening total carotenoid was carried out on four isolated microalgae species and two microalgae species were obtained from biochemistryy laboratory such as Scenedesmus rubescens and Galdiera sulphuraria. The highest total carotenoid content was microalgae isolated from pond water with belong to chlorophyta genus with carotenoid content $36 \pm 0.25 \mu / g$. These results provide information that the isolated microalgae can be used as potential as a source and production of carotenoids.
\end{abstract}

Key words : Isolation, Microalgae, Carotenoid

\section{PENDAHULUAN}

Mikroalga adalah mikroorganisme yang dapat berfotosintesis dengan memanfaatkan sumber cahaya matahari (Duong et al. 2012) Mikroalga mengandung senyawa metabolit primer dan metabolit sekunder yang dapat dimanfaatkan sebagai sumber bahan makanan fungsional, nutrasetik dan farmasetik. Metabolit primer yang dilaporkan terdapat pada mikroalga diantaranya adalah karbohidrat, lipid, protein serta kandungan metabolit sekunder seperti, terpenoid, saponin, dan pigmen karotenoid meliputi astaxantin, lutein, $\beta$-karoten yang bermanfaat dalam bidang kesehatan sebagai sumber obat (Fu et al. 2017).

Senyawa bioaktif dari mikroalga yang banyak ditemukan diantaranya adalah pigmen alami yang terdiri atas klorofil, karotenoid dan phycobiliprotein(Gouveia, Marques, and Bandarra 2010). Pigmen tersebut telah banyak digunakan dalam berbagai industri makanan 
sebagai pewarna alami, serta industri kosmetik dan farmasi (Tan et al. 2020). Karotenoid adalah senyawa organik poliena isoprenoid yang diklasifikasikan menjadi golongan tetraterpenoid dengan 40 atom karbon sebagai atom penyusunnya (Zhang et al. 2014). Karotenoid dibagi menjadi dua yaitu, karoten (hidrokarbon yang tidak mengandung oksigen) seperti $\alpha$ karoten, $\beta$-karoten dan likopen, dan xantophylls (hidrokarbon yang mengandung unsur oksigen) termasuk lutein, zeaxanthin dan violaxanthin (Aburai et al. 2013). Beberapa penelitian telah melaporkan kandungan senyawa bioaktif seperti tokoferol, karotenoid dan fikosianin dari mikroalga Nannochloropsis sp, Spirulina maxima, Tetraselmis suecica, Synechoccocus, Synechoccocus dan Porphiridium cruentum (Santiago-morales, Trujillo-valle, and Márquezrocha 2018). Mikroalga Chlorella vulgaris dilaporkan mempunyai kandungan karotenoid seperti $\quad \beta$-karoten,Lutein, Astaxantin, Cantaxantin,dan Zeaxantin (Hynstova et al. 2018). Penelitian lainnya melaporkan mikroalga Oedogonium intermedium mengandung karotenoid seperti Violaxantin, Neoxantin, Loroxantin, Lutei, $\alpha$-karoten, $\beta$-karoten, dan 9'cis-Neoxantin yang mempunyai aktivitas biologi sebagai antioksidan dan antidiabetes(Wang et al. 2017).

Berdasarkan uraian potensi yang dimiliki oleh mikroalga, maka dilakukan penelitian yang bertujuan untuk mendapatkan mikroalga dari sumber air kolam Universitas Andalas Padang dan penapisan kandungan karotenoidnya.

\section{BAHAN DAN METODE}

\section{Bahan}

Bahan yang digunakan dalam penelitian ini adalah mikroalga yang telah berhasil diisolasi dan menjadi koleksi Laboratorium Biokimia Universitas Andalas (Hernandi, Dharma, and Armaini 2019) yaitu Scenedesmus rubescens dan Galdiera sulphuraria. Mikroalga yang diisolasi dari sumber perairan air kolam Universitas Andalas yang diberikan kode isolat AUP-1, AUP-2, AUP-3 dan AUP-4. Bahan yang digunakan dalam penelitian ini meliputi media Bold's Basal Medium (BBM) yang terdiri dari natrium nitrat (Merck), magnesium sulfat heptahidrat (Merck), natrium klorida (Merck), kalium hidrogen fosfat (Merck), kalium dihidrogen fosfat (Merck), kalsium klorida dihidrat (Merck), asam borat (Merck), kalium hidroksida (Merck), EDTA, besi sulfat heptahidrat (Merck), asam sulfat (Merck), zink sulfat heptahidrat (Merck), mangan (II) klorida tetrahidrat (Merck), molibdenum trioksida (Merck), tembaga sulfat pentahidrat (Merck), kobalt (II) nitrat heksahidrat (Merck), akuades, kloroform (Merck), dan methanol (Merck).

\section{Metode \\ Pengambilan Sampel Mikroalga}

Pengambilan sampel mikroalga dilakukan dengan menggunakan menggunakan plankton net dengan ukuran mata jaring $30 \mu \mathrm{m}$ dan diameter mulut jaring $30 \mathrm{~cm}$ dengan teknik secara vertikal pada kedalaman 0-0,5 m dar permukaan sumber perairan kolam Universitas Andalas. Jaring plankton net ditenggelamkan dalam perairan dan selanjutnya diangkat. Sampel air yang telah disaring oleh plankton net dimasukan ke dalam botol yang sudah diisi dengan medium BBM dan diberi label untuk selanjutnya dilakukan identifikasi dan isolasi mikroalga dengan menggunakan bantuan mikroskop (Acid et al. 2009; Kawaroe et al., 2010).

\section{Isolasi Mikroalga}

Teknik isolasi mikroalga dalam penelitian ini dilakukan dengan metode micropipette washing technique (Parvin, 2007). Bagian ujung mikropipet dipanaskan dan selanjutnya dibentuk menjadi bentuk lancip. Sampel mikroalga yang sudah dikumpulkan dan dibawa ke laboratorium selanjutnya dimasukkan dalam BBM. Selanjutnya mikropipet akan digunakan untuk mengambil sel tunggal mikroalga dari sampel air. Sel tunggal mikroalga diamati dengan menggunakan mikroskop (Olympus BX40) pada perbesaran 1000x. Setelah diperoleh isolat murni mikroalga, selanjutnya isolate mikroalga akan ditempatkan dalam botol vial $10 \mathrm{~mL}$ dan ditambahkan BBM. Botol vial diletakkan di dekat sinar cahaya lampu neon putih (Phillips TL-D 40 W) sampai \pm 7 hari. Kemudian dilakukan pengecekan kembali dengan mikroskop, jika sudah diperoleh satu sel tunggal dibawah pengamatan mikroskop, maka mikroalga tersebut sudah murni dan selanjutnya dilakukan proses kultivasi dalam medium BBM.

\section{Kultur Mikroalga}

Mikroalga dikultur dengan menggunakan media BBM dengan kondisi pencahayaan menggunakan sebuah sinar cahaya lampu neon putih (Phillips TL-D $40 \mathrm{~W}$ ) dengan intensitas cahaya \pm 2219 Lux. Aerasi dilakukan dengan menggunakan aerator selama proses kultur mikroalga. Pertumbuhan mikroalga dimonitor secara berkala dengan melakukan pengukuran optical density (OD) pada panjang gelombang $680 \mathrm{~nm}$ dengan Spektrofotometer UV-Vis (Genesys 20). Kurva pertumbuhan mikroalga yang diperoleh digunakan untuk menentukan waktu pemanenan biomassa mikroalga. Pemanenan mikroalga dilakukan dengan melakukan sentrifugasi menggunakan alat sentrifus (Centrifuge 80-2 Electric Centrifuge) terhadap kultur mikroalga dan diambil biomassanya untuk dikeringkan (Sekatresna et al. 2016). 


\section{Skrining Mikroalga Terhadap Total Karotenoid}

Skrining total karotenoid dalam penelitian ini dilakukan untuk mendapatkan spesies mikroalga dengan kandungan total karotenoid yang paling tinggi. Biomassa mikroalga ditimbang sebanyak $20 \mathrm{mg}$ dan ditambahkan dengan $5 \mathrm{~mL}$ metanol kemudian diinkubasi dalam penangas air selama 30 menit pada $40 \pm 5$ ${ }^{\circ} \mathrm{C}$ dan didinginkan pada suhu ruang. Campuran biomassa mikroalga dan metanol kemudian disentrifugasi pada $3500 \mathrm{rpm}$ selama 10 menit. Pigmen terlarut diukur absorbansinya dengan spektrofotometer UV-Vis pada panjang gelombang $470 \mathrm{~nm}, 652 \mathrm{~nm}$, dan $665 \mathrm{~nm}$. Selanjutnya absorbansi diukur dengan menggunakan spektrofotometer UV-Vis dengan menggunakan rumus penyerapan pigmen maksimum yaitu pigmen (klorofil a, klorofil b dan Karotenoid) pada 470, 652 dan 665 nm. Penentuan kadar total karotenoid dilakukan dengan menggunakan rumus perhitungan total karotenoid (Lichtenthaler 1987) :

Klorofil a $(\mu \mathrm{g} / \mathrm{g})=(16,72 \times \mathrm{A} .665 \mathrm{~nm})-(9,16 \times \mathrm{A} .652 \mathrm{~nm})$
Klorofil b $(\mu \mathrm{g} / \mathrm{g})=(34,09 \times \mathrm{A} .652 \mathrm{~nm})-(15,2 \times \mathrm{A} .665 \mathrm{~nm})$

Total Karotenoid $(\mu \mathrm{g} / \mathrm{g})$

$=\frac{(1000 \times \text { A.470 nm })-(1,63 \times \text { Chlo a })-(104,96 \times \text { Chlo } \mathrm{b})}{221}$

\section{HASIL DAN PEMBAHASAN}

\section{Isolasi Mikroalga dan Identifikasi Mikroalga}

Isolasi spesies mikroalga dari sampel air kolam di Universitas Andalas dilakukan dengan metode micropipette washing technique (Parvin, 2007). Berdasarkan hasil isolasi diperoleh empat isolat mikrolga yang selanjutnya ditumbuhkan dengan menggunakan media BBM. Selain itu, dalam penelitian ini juga dilakukan penapisan terhadap 2 isolat mikroalga koleksi Laboratorium Biokimia Universitas Andalas Scenedesmus rubescens dan Galdiera sulphuraria. (Hernandi, Dharma, and Armaini 2019). Hasil identifikasi morfologi dari empat isolat tersebut dapat dilihat pada Gambar 1 terkait morfologi mikroalga hasil isolasi.
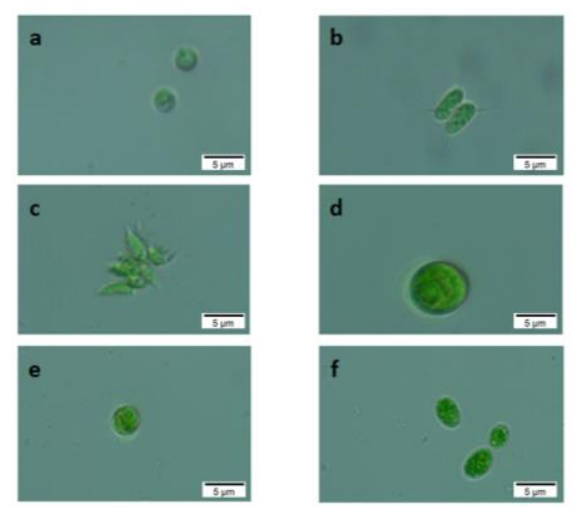

Gambar 1. Bentuk morfologi isolat (a) AUP-1 (b) AUP2, (c) AUP-3 dan (d) AUP-4 (Hasil isolasi) dan

(e)Scenedesmus rubescens AUMA1 (f) Galdiera sulphuraria AUMA2

Hasil identifikasi morfologi spesies memberikan informasi tentang karakter fenotip dari mikroalga yang berhasil dipisahkan seperti bentuk, warna, dan ukuran dari mikroalga yang berhasil dipisahkan. Berdasarkan karakter tersebut keempat isolat mikroalga menunjukkan bahwa empat mikroalga hasil isolasi dari kolam Universitas Andalas dengan mempunyai warna hijau dengan bentuk bulat dan memanjang. Berdasarkan penelusuran literatur dan website Algabase, keempat isolat tersebut memperlihatkan karakter umum yang dimiliki mikroalga yang berasal dari kelas chlorophyta (alga hijau) (Kawaroe,2010). Mikroalga dari kelas chlorophyta banyak ditemukan pada sumber perairan air tawar, seperti spesies mikroalga yang berasal dari sumber Sungai Kati Lubuk Linggau, Sumatera Selatan umumnya didominasi mikroalga dari kelas chlorophyta meliputi Oocystis sp, Scenedesmus sp, Pediastrum sp, Cosmarium $s p$ dan Chlorella $s p$ (Harmoko et al. 2017).

\section{Kultivasi Mikroalga dan Skrining Total Karotenoid Mikroalga \\ Mikroalga ditumbuhkan dengan} menggunakan medium pertumbuhan BBM. Medium BBM adalah salah satu jenis BBM yang banyak digunakan untuk proses kultur mikroalga air tawar karena mempunyai kesamaan karakteristik dengan air tawar pada kondisi alami (Aragaw and Asmare, 2017). Mikroalga isolat AUP-2 dan AUP-3 mempunyai nilai optical density (OD) tertinggi dibandingkan jenis isolat mikroalga lainnya dan Nilai OD terendah adalah mikroalga Scenedesmus rubescens AUMA1. Nilai OD menggambarkan kerapatan sel mikroalga selama masa pertumbuhan (Aragaw and Asmare 2017). 


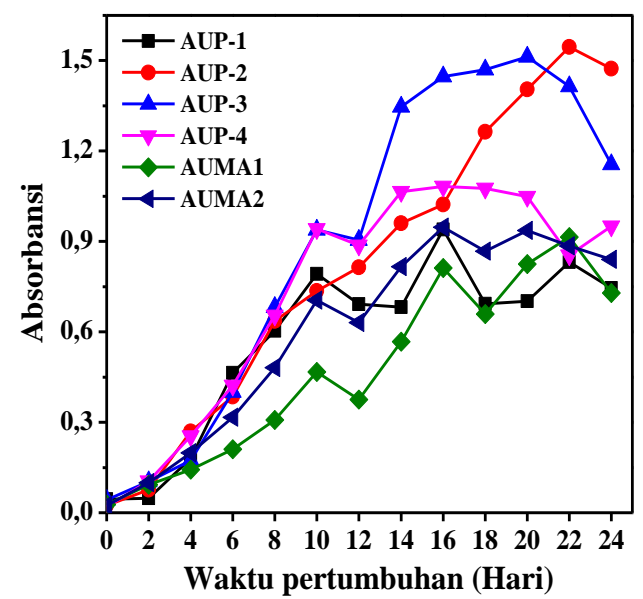

Gambar 2. Kurva pertumbuhan mikroalga

Pertumbuhan isolat mikroalga diukur berdasarkan peningkatan absorban pada kultur yang diukur menggunakan spektrofotometer UVVis pada panjang gelombang $680 \mathrm{~nm}$. Nilai absorban pada kurva pertumbuhan mewakili jumlah kepadatan sel pada media kultur. Tingginya nilai absorbansi hasil pengukuran mengindikasikan semakin banyak jumlah sel pada media pertumbuhan isolat mikroalga (Chaidir at al., 2017).

Kultivasi isolat mikroalga dalam medium BBM mengalami peningkatan dari hari ke-0 sampai hari ke-16 dan megalami penurunan pada hari ke-22. Absorban yang diperoleh mewakili jumlah sel mikroalga yang terdapat dalam medium kultivasi BBM. Kepadatan sel dapat diperlihatkan dengan semakin tingginya nilai absorban pada kurva pertumbuhan isolat mikroalga (Hernandi, Dharma, and Armaini 2019). Kepadatan sel tertinggi diperlihatkan oleh isolat AUP-2 dan AUP-3. Berdasarkan hasil yang diperoleh dari kurva pertumbuhan secara keseluruhan mengalami penurunan kepadatan sel pada hari ke-20 sampai pada hari ke-24. Kurva pertumbuhan mikroalga dapat dijadikan referensi dalam menentukan waktu pemanenan optimal terhadap mikroalga (Sekatresna et al. 2016). Biomassa mikroalga yang sudah dilakukan pemanenan pada waktu optimal, kemudian dipisahkan dari medium dan dihilangkan kadar airnya dengan cara didiamkan pada suhu ruang selama $\pm 1-2$ hari untuk mendapatkan berat kering biomassa mikroalga dengan melakukan penimbangan berat biomasa mikroalga sampai beratnya konstan.

Berat biomassa mikroalga dalam penelitian ini dihitung secara gravimetri dengan menggunakan neraca analitik. Data berat biomassa mikroalga yang ditkultivasi dalam $500 \mathrm{~mL}$ BBM disajikan dalam Tabel 1. Biomassa ini selanjutnya disimpan dalam lemari pendingin sebelum digunakan dalam skrining penentuan kandungan total karotenoid setiap isolat mikroalga dalam penelitian ini.

Tabel .1 Berat Biomassa Mikroalga (Rata-rata \pm Standar Devisiasi mewakili jumlah ulangan $n=3$ ).

\begin{tabular}{cccc}
\hline No & Mikroalga & Sumber & Berat Biomassa $(\mathrm{g})$ \\
\hline 1 & AUP-1 & Kolam Unand & $0,5848 \pm 0,11$ \\
\hline 2 & AUP-2 & Kolam Unand & $0,4770 \pm 0,14$ \\
\hline 3 & AUP-3 & Kolam Unand & $0,8856 \pm 0,27$ \\
\hline 4 & AUP-4 & Kolam Unand & $0,6676 \pm 0,12$ \\
\hline 5 & AUMA 1 & Danau Kerinci & $0,4952 \pm 0,17$ \\
\hline 6 & AUMA 2 & Danau Kerinci & $0,5664 \pm 0,22$ \\
\hline
\end{tabular}

Klorofil dan karotenoid merupakan pigmen yang banyak ditemukan pada organisme fotosintetik seperti mikroalga(Qamar et al. 2021). Biosintesis karotenoid terjadi pada kloroplas, yang terbentuk oleh kondensasi universal C5 prekursor isoprenoid isopentenil difosfat (IPP) dan dimethylallyl pyrophosphate (DMAPP). Kedua prekursor ini diproduksi oleh dua jalur biosintesis dalam tumbuhan yaitu jalur mevalonat (MVA) dan jalur methylerythritol 4phosphate (MEP) (Zhang et al. 2014). Dalam mikroalga karotenoid disintesis melalui jalur nonmevalonat yakni jalur methylerythritol 4phosphate (MEP), dimana molekul isoprenoid (C5) dikonversi secara enzimatik menjadi tetraterpenoid (C40) (Barredo 2012). Warna hijau pada mikroalga disebabkan oleh adanya kandungan klorofil. Karotenoid pada mikroalga ditandai dengan adanya perubahan warna hijau menjadi kuning selama proses kultivasi mikroalga. Karotenoid seperti $\beta$-karoten, $\alpha$ - karoten, lutein, violaxanthin, neoxanthin dan zeaxanthin merupakan bebrapak jenis karotenoid yang banyak diperoleh dari mikroalga (Priyadarshani and Rath 2012). Berdasarkan hasil skrining terhadap produksi biomassa isolat mikroalga AUP-1, AUP-2, AUP-3, AUP-4, AUMA 1 dan AUMA 2 diperoleh berat biomassa secara berurutan adalah $0,5848 \pm 0,11 \mathrm{~g}, 0,4770 \pm 0,14 \mathrm{~g}$, $0,8856 \pm 0,27 \mathrm{~g}$,

$0,6676 \pm 0,12 \mathrm{~g}, 0,4952 \pm 0,17 \mathrm{~g}$, dan $0,5664 \pm 0,22$ g. Isolat mikoalga dengan kode isolat AUP-3 mempunyai berat biomassa paling banyak jika dibandingkan dengan isolat lainnya.

Pada Tabel 1 menunjukkan jumlah bio massa terbanyak terdapat pada mikroalga isolat AU P-3 dengan jumlah biomassa sebanyak 0,8 $856 \pm 0,27 \mathrm{~g}$, kemudian isolat mikroalga AUP-2 dengan berat biomassa terendah sebanyak 0,4 770 $\pm 0,14$. Perbedaan biomassa pada spesies mikroalga disebabkan kemampuan biosintesis klorofil tidak sama 
antar spesies satu dengan spesies yang lain (Chew et al. 2017).

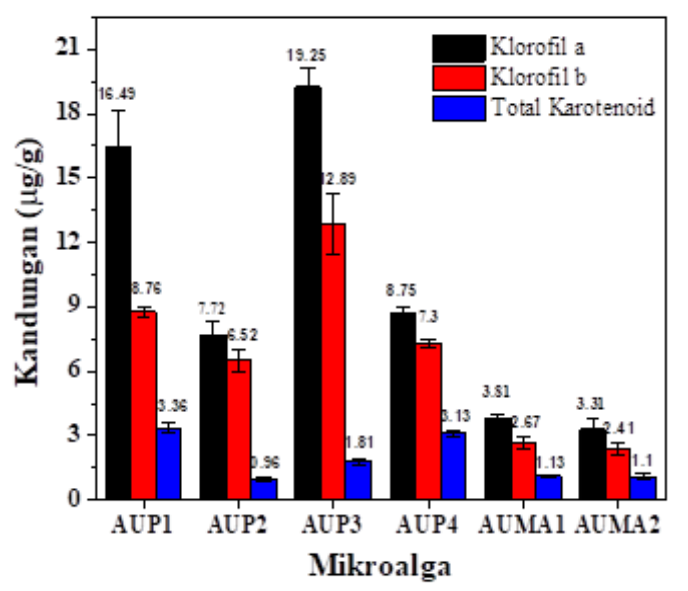

Gambar 3. Kandungan Klorofil a, Klorofil b dan Total Karotenoid Mikroalga

Berdasarkan hasil pengukuran klorofil a, klorofil b pada dan total karotenoid terhadap enam jenis isolat mikroalga didapatkan kandungan klorofil a dan klorofil tertinggi adalah isolat AUP-3 yaitu $19,29 \mu \mathrm{g} / \mathrm{g}$ dan $12,89 \mu \mathrm{g} / \mathrm{g}$. Hasil skrining total karotenoid secara berurutan adalah sebesar $3,36 \pm 0,25 \mu \mathrm{g} / \mathrm{g}, 0,96 \pm 0,10 \mu \mathrm{g} / \mathrm{g}$, $1,81 \pm 0,14 \mu \mathrm{g} / \mathrm{g}, 3,13 \pm 0,14 \mu \mathrm{g} / \mathrm{g}, 1,13 \pm 0,08 \mu \mathrm{g} / \mathrm{g}$, $1,13 \pm 0,08 \mu \mathrm{g} / \mathrm{g}$, dan $1,10 \pm 0,16 \mu \mathrm{g} / \mathrm{g}$ berat kering biomassa. Mikroalga isolat AUP-1 mempunyai kandungan total karotenoid tertinggi sebesar $3,36 \pm 0,25 \mu \mathrm{g} / \mathrm{g}$. Korelasi antara konsentrasi klorofil a, klorofil b, karotenoid dan biomassa mikroalga, ditegaskan dalam penelitian oleh Mencfel (2013) yang menyebutkan tingginya biomassa mikroalga belum tentu mempunyai kandungan klorofil dan karotenoid yang tinggi juga, yang disebabkan oleh beberapa faktor seperti kemampuan adaptasi mikroalga terhadap kondisi intensitas cahaya, kemampuan mikroalga dalam menyerap, dan kemampuan mikroalga dalam menyerap nutrisi yang terdapat dalam media. Metabolisme pada mikroalga melibatkan berbagai enzim penting dalam proses metabolism seperti pyruvate dehydrogenase complex (PDC) dan acetyl-CoA carboxylase (ACCase) yang berperan selama proses pertumbuhan sel dan biosintesis lipid dan karotenoid mikroalga (Dębowski et al. 2020).

\section{KESIMPULAN}

Berdasarkan hasil identifikasi secara morfologi dan penapisan kandungan total karotenoid terhadap mikroalga hasil isolasi maka dapat diperoleh hasil enam isolat mikroalga dari genus chlorophyta mempunyai bentuk bulat dan berwarna hijau. Mikroalga isolate AUP-1 merupakan isolat dengan kandungan total karotenoid tertinggi sebesar $3,36 \pm 0,25 \mu \mathrm{g} / \mathrm{g}$ berat kering biomassa. Hasil studi penelitian ini dapat memberikan informasi mikroalga dari genus chlorophyta mempunyai potensi untuk dijadikan sebagai sumber dan produksi karotenoid.

\section{UCAPAN TERIMA KASIH}

Penulis berterima kasih kepada KementrianRiset dan Pendidikan Tinggi Republik Indonesia (KEMENRISTEKDIKTI) atas dukungan finansial melalui program beasiswa Program Magister Menuju Doktor Untuk Sarjana Unggul (PMDSU) [No Kontrak .146/SP2LH/LT/DRPM/2018].

\section{DAFTAR PUSTAKA}

Aburai, Nobuhiro, Satoshi Ohkubo, Hideaki Miyashita, and Katsuya Abe. 2013. "Composition of Carotenoids and Identification of Aerial Microalgae Isolated from the Surface of Rocks in Mountainous Districts of Japan." Algal Research 2 (3): 237-43.

https://doi.org/10.1016/j.algal.2013.03.001.

Acid, Docosahexaenoic, D H A Production, Huey-lang Yang, Chung-kuang Lu, Shu-fen Chen, Young-mao Chen, and Yi-min Chen. 2009. "Isolation and Characterization of Taiwanese Heterotrophic Microalgae: Isolation and Characterization of Taiwanese Heterotrophic Microalgae: Screening of Strains for Docosahexaenoic Acid ( DHA ) Production," no. August. https://doi.org/10.1007/s10126-009-9207-0.

Aragaw, Tadele Assefa, and Abraham M Asmare. $2017 . \quad$ "Experimental Identifications of Fresh Water Microalgae Species and Investigating the Media and $\mathrm{PH}$ Effect on the Productions of Microalgae." Journal of Environmental Treatment Techniques 5 (2): 124-31. http://www.jett.dormaj.com/docs/Volume5/l ssue 4/Experimental Identifications of Fresh Water Microalgae Species and Investigating the Media and $\mathrm{PH}$ Effect on the Productions of Microalgae.pdf.

Barredo, José-Luis. $2012 . \quad$ "Microbial Carotenoids from Bacteria and Microalgae. Methods and Protocols." Series: Methods in Molecular Biology, Vol. 892892 (April): 355. https://doi.org/10.1007/978-1-61779879-5.

Chaidir, Zulkarnain, Melysa Putri, and May June. 2017. "Research Journal of Pharmaceutical , Biological and Chemical Sciences Isolation and Identification of Microalgae from Harau Valley Payakumbuh, West Sumatra as One Agent Producing Compounds Antibacterial ." Research Journal of Pharmaceutical, Biological and Chemical Sciences Isolation 8 (1950): 1950-57. 
Chew, Kit Wayne, Jing Ying Yap, Pau Loke Show, Ng Hui Suan, Joon Ching Juan, Tau Chuan Ling, Duu-jong Lee, and Jo-shu Chang. 2017. "Microalgae Biorefinery: High Value Products Perspectives." Bioresource Technology. https://doi.org/10.1016/j.biortech.2017.01.0 06.

Communication, Short. 2007. "Two Important Techniques for Isolation of Microalgae" 20: 117-24.

Dębowski, Marcin, Marcin Zieliński, Joanna Kazimierowicz, Natalia Kujawska, and Szymon Talbierz. 2020. "Microalgae Cultivation Technologies as an Opportunity for Bioenergetic System DevelopmentAdvantages and Limitations." Sustainability

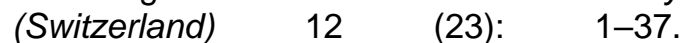
https://doi.org/10.3390/su12239980.

Duong, Van Thang, Yan Li, Ekaterina Nowak, and Peer M. Schenk. 2012. "Microalgae Isolation and Selection for Prospective Biodiesel Production." Energies 5 (6): 1835-49. https://doi.org/10.3390/en5061835.

Fu, W., D. R. Nelson, Z. Yi, M. Xu, B. Khraiwesh, K. Jijakli, A. Chaiboonchoe, et al. 2017. "Bioactive Compounds From Microalgae: Current Development and Prospects." Studies in Natural Products Chemistry 54 (November 2019): 199-225. https://doi.org/10.1016/B978-0-444-639295.00006-1.

Gouveia, Luisa, Ana Evangelista Marques, and Narcisa M Bandarra. 2010. "Microalgae Source of Natural Bioactive Molecules as Functional Ingredients," no. June. https://doi.org/10.1616/1476-2137.15884.

Hernandi, Riska, Abdi Dharma, and A Armaini. 2019. "Penapisan, Isolasi, Dan Karakterisasi Mikroalga Yang Berpotensi Sebagai Sumber Biodiesel Dari Perairan Danau Kerinci, Jambi." Jurnal Litbang Industri $\quad 9 \quad$ (1): 41. https://doi.org/10.24960/jli.v9i1.4326.41-49.

Hynstova, Veronika, Dagmar Sterbova, Borivoj Klejdus, Josef Hedbavny, Dalibor Huska, and Vojtech Adam. 2018. "Journal of Pharmaceutical and Biomedical Analysis Separation , Identification and Quantification of Carotenoids and Chlorophylls in Dietary Supplements Containing Chlorella Vulgaris and Spirulina Platensis Using High Performance Thin Layer Chromatography." Journal of Pharmaceutical and Biomedical Analysis 148:

108-18.

https://doi.org/10.1016/j.jpba.2017.09.018.

Kawaroe, Mujizat, Partono Tri, Andriani. 2010. Mikroalga Potensi Dan Pemanfaatannya Untuk Produksi Bio Bahan Bakar.

Lichtenthaler, Hartmut K. 1987. "Chlorophyll and
Carotenoid Determination: Pigments of Photosynthetic Biomembranes." Methods in Ensymology 8 (148): 349-82.

Mencfel, R. 2013. "Relationship Among Biomass Of Algae And Concentration Of Chlorophyll A , Against The Taxonomic Structure Ofphytoplankton In Three Lakes On Lublin Polesie Region." Teka Kom. Ochr. Kszt. ?Rod. Przyr. - OL PAN 10: 243-49.

Mikroalga, Keanekaragaman, D I Sungai, Kati Kota, H Armoko, S Epriyaningsih, Sungai Megang, Sungai Kelingi, Sungai Mesat, Sungai Beliti, and Sungai Kati. 2017. "Lubuklinggau" 4 (September): 201-5.

Priyadarshani, Indira, and Biswajit Rath. 2012. "Commercial and Industrial Applications of Micro Algae - A Review" 3 (4): 89-100.

Qamar, Hina, Kashif Hussain, Aishwarya Soni, Anish Khan, Touseef Hussain, and Benoît Chénais. 2021. "Cyanobacteria as Natural Therapeutics and Pharmaceutical Potential: Role in Antitumor Activity and as Nanovectors." Molecules 26 (1): 247. https://doi.org/10.3390/molecules26010247

Santiago-morales, Ivonne Sandra, Lourdes Trujillo-valle, and Facundo Joaquín Márquez-rocha. 2018. "Tocopherols , Phycocyanin and Superoxide Dismutase from Microalgae: As Potential Food Antioxidants" 5 (1): 19-27.

Sekatresna, Widiyanti, Abdi Dharma, Rahmiana Zein, and Zulkarnain Chaidir. 2016. "Identification of Blue-Green Algae Uncultured Oscillatoria Sp IPOME-4 Isolated from Local Industry Effluent with The Potential as $\beta$-Carotene Feedstock" 8 (12): 110-17.

Tan, Jia Sen, Sze Ying Lee, Kit Wayne Chew, Man Kee Lam, Jun Wei Lim, Shih Hsin Ho, and Pau Loke Show. 2020. "A Review on Microalgae Cultivation and Harvesting, and Their Biomass Extraction Processing Using Ionic Liquids."Bioengineered 11(1):116-29. https://doi.org/10.1080/21655979.2020.171 1626.

Wang, Na, Yuki Manabe, Tatsuya Sugawara, Nicholas A Paul, and Jian Zhao. 2017. "School of Chemical Engineering, The University of New South Wales, Sydney, New Faculty of Science, Health, Education and Engineering, University of the Sunshine Corresponding Author: Jian Zhao." Food Chemistry. https://doi.org/10.1016/j.foodchem.2017.09 .075 .

Zhang, Jie, Zheng Sun, Peipei Sun, Tianpeng Chen, and Feng Chen. 2014. "Microalgal Carotenoids: Beneficial Effects and Potential in Human Health." Food and Function 5 (3): $413-25$. https://doi.org/10.1039/c3fo60607d. 